\title{
FACTORS AND PRACTICES IMPROVING STUDENT COMPLETION RATE: A COMPARISON OF TWO DISTANCE LEARNING COURSES
}

\author{
Rocky Y. K. Fan \\ Linda Y. K. Lee \\ The Open University of Hong Kong
}

\begin{abstract}
Numerous approaches have been attempted to tackle the problem of student attrition in open and distance education. To increase the retention rate, many of these approaches concentrated on the problem and emphasised on rectifying factors that contribute to the attrition. Literature has sometimes overlooked the reasons that promote student retention. To gain insights from successful examples, this study compares the characteristics of a nursing course with a $91 \%$ completion rate and a mathematics course with $46 \%$. It aims to identify factors and practices that improve the quality of an open and distance learning course, its students, and hence the completion rate. The two courses for comparison are similar in many aspects such as being 10-credit foundation courses, having similar student support, and presenting under the same set of university policies; nevertheless, there are significant differences between them.
\end{abstract}

Keywords: completion rate, Open University of Hong Kong, career advancement

\section{MOTIVATION}

Student attrition, on foundation courses in particular, is a long-standing problem concerning open and distance education (Fan and Chan, 1999). To understand the phenomenon for improving student completion, the attrition problem has been discussed in extensive literature for decades. Many existing works focused on the problem itself and considered factors that contribute to student attrition. In addition, they usually concentrated on one aspect of the problem. For instance, by comparing the help-seeking strategies between high-achieving and low-achieving students, Taplin et al (2001) identified some students' weaknesses associated with student attrition. Frameworks and related student support services can then be developed based on the findings. Research results have shown that addressing the attrition factors is an effective approach to reduce the attrition rate. Nonetheless, high attrition rates are still very common in open and distance education. To build up knowledge on the attrition problem and develop strategies for further enhancement of student completion, an integrated approach to study the problem in various aspects should be promoted for future research works.

At the Open University of Hong Kong (OUHK), foundation courses often possess very high non-completion rates and the rates exceed $70 \%$ in some cases. In the same system, however, a few foundation courses perform extremely well and their non-completion rates are less than $10 \%$. It is sensible to assume that the high-achieving courses possess some characteristics that contribute to the better performance. For improving the completion rates of the low- 
achieving courses, it is therefore meaningful to identify these positive characteristics and manipulate the findings. In this study, various characteristics of a high-achieving course and a low-achieving course will be compared and analyzed. An integrated approach will be adopted to study their differences in four aspects, namely, course design and structure, course requirements, course management, and rewards and penalties of studying the courses. It is hoped that through the successful experience, factors and practices that enhance the quality of an open and distance learning course and its students can be identified, and strategies can be defined and applied accordingly to increase the student completion rate.

\section{TWO COURSES}

In this study, two foundation courses offered at the OUHK are chosen for discussion. The two courses are NU101C Life Sciences and M122 A Foundation in Applied Mathematics. NU101C is chosen for its outstanding completion rate and M122 is a typical course for comparison. NU101C is designed mainly for the Higher Diploma in Nursing programme, a conversion programme that aims to upgrade the local Enrolled Nurses to Registered Nurses. M122 is provided for students pursuing mathematics or applied science degrees. It aims to develop the analytical skills and mathematical techniques of its students for further studies.

Table 1 summarizes the course results of NU101C and M122 for the 2002 and 2003 course presentations. The results show that the performances of each course were consistent over presentations. In each presentation, the submission rates of the first assignment show that the initial student participation rates of the two courses were not significantly different; however, the examination results indicate that the students of NU101C were more persistent on the course and better prepared for the final examination. The non-completion rate of M122 was about four to five times larger than that of NU101C.

Table 1: Course results of NU101C and M122

\begin{tabular}{lcccc}
\hline & \multicolumn{2}{c}{ NU101C } & \multicolumn{2}{c}{ M122 } \\
\cline { 2 - 5 } & 2002 & 2003 & 2002 & 2003 \\
\hline Submission rate of first assignment & $99 \%$ & $100 \%$ & $93 \%$ & $93 \%$ \\
Attendance rate of examination & $97 \%$ & $97 \%$ & $62 \%$ & $59 \%$ \\
Passing rate of examination & $94 \%$ & $94 \%$ & $83 \%$ & $77 \%$ \\
Overall course completion rate & $90 \%$ & $91 \%$ & $51 \%$ & $46 \%$ \\
\hline
\end{tabular}

Despite having very different completion rates, NU101C and M122 possess many common characteristics. Basically, these courses are developed by the OUHK and presented under the same set of university policies. They adopt an open assess policy and run in a distance learning mode with limited face-to-face support. In addition, both of them are 10-credit and two-semester foundation courses, offered in April each year, assessed with assignments and examinations, supported by part-time tutors and overseen by course coordinators.

\section{DIFFERENCES BETWEEN NU101C AND M122}

The quality assurance system at the OUHK ensures that the development and presentation of both NU101C and M122 have met a satisfactory standard. It is sensible to assume that some characteristics of $\mathrm{NU} 101 \mathrm{C}$ have contributed to its outstanding completion rate. Taking the 
similarities of the two courses as the background, this section considers their differences in four aspects, namely, course design and structure, course requirements, course management, and rewards and penalties of studying the courses.

\section{Course Design and Structure}

NU101C is designed specifically for a professional programme in nursing. The programme targets at professional students, practising Enrolled Nurses in Hong Kong, and is accredited by an external professional body, the Nursing Council of Hong Kong. This organization is responsible for nursing registration in Hong Kong.

In general, the Nursing Council of Hong Kong requires students to complete the nursing programme within three years. To facilitate students to meet this requirement, a three-year study schedule of the nursing programme is pre-determined and provided. Although this is only a suggested schedule, most of the students enrolling on the programme follow it closely and take NU101C as their first course.

The core courses in the nursing programme are designed to have the same structure. As for other core courses, the medium of instruction of NU101C is Chinese, the first language of most of its students. In addition, NU101C has five written assignments for continuous assessment and the best four will be counted towards the final score.

On the contrary, M122 does not target at any particular professional group. This course is designed to fit in various mathematics and applied science degree programmes. All of these programmes do not have any study schedules suggested for their students. M122 is delivered in English and consists of ten assignments including five written and five multiple-choicequestion assignments. All ten assignments are required for continuous assessment. In general, students enrolled on M122 can have very different backgrounds and progress along their intended programmes at their own paces.

\section{Course Requirements}

In principle, both NU101C and M122 apply an open access policy and do not have any entry requirements. Owing to the professional nature, however, students enrolling into the nursing programme must have fulfilled certain entry requirements. These requirements include both academic and professional qualifications and relevant working experience. Counselling and advice will be given to those who have not fulfilled the requirements and would like to take NU101C. In the past, all students of NU101C had fulfilled the requirements.

Students in distance learning courses such as M122 are usually not required to attend face-toface sessions. The nursing students, however, are required to attend at least $80 \%$ of the faceto-face sessions in the nursing courses including NU101C for the academic qualification to be accredited by the Nursing Council of Hong Kong. In addition, failing M122 may simply slow down one's progress. For nursing students, the consequence of failing NU101C can be severe since they are required to complete the programme within three years. 
In the OUHK, all tutors are required to possess certain qualifications. An honours degree is usually a minimum requirement. M122 requires its tutors to possess at least an honours degree in mathematics or a related discipline. Teaching experience is an asset but not a requirement. For NU101C, in addition to an honours degree, tutors are also required to be Registered Nurses with relevant professional experience. In the past, all tutors of NU101C possessed higher degrees in nursing.

\section{Course Management}

In the OUHK, course schedules are prepared independently by their course coordinators. Based on the pre-determined study schedule, however, the course schedules in the nursing programme are arranged as a whole to prevent study conflicts. For instance, the tutorial schedules of the first (NU101C) and second courses in the programme are arranged together so that students taking these courses can attend their tutorials in the same weekday evenings. In addition, the assessment dates for the two courses are scheduled in different periods such that the study load of students taking these courses can be distributed more evenly. This practice is not implemented for M122 because its students can study various combinations of courses. As a result, students taking M122 and other courses together may encounter conflicts in their schedules. Some of these conflicts may be solved with special rearrangements. For the others such as having two tutorials at the same time, students may need to make a choice and sacrifice one of them.

Many students studying distance learning courses study independently. Their contact with tutors and other students are usually limited to the scheduled activities such as face-to-face tutorials. In addition, they seldom communicate with course coordinators who manage the courses. Students in both NU101C and M122 are encouraged to form peer-support groups, but these groups do not help improving the communication between them and their course coordinators. To enhance class management and communication, a student representative is selected for each tutorial group in NU101C with the assistance of its tutor. The representative aims to strengthen the relationship and understanding between students and the university. In particular, the representative will coordinate student affairs and communications between the tutorial group and course coordinator.

\section{Rewards and Penalties}

A number of rewards are offered specifically to the students of the nursing programme. The rewards include scholarships for taking the theoretical courses and exemption of clinical hours for the practicum course. The former is a monetary award for outstanding academic performance and the latter implies that a shorter practicum period is required for having relevant working experience. Upon successful completion of the nursing programme, the students will obtain an academic qualification as well as a professional qualification. The academic qualification is the Higher Diploma in Nursing and the professional one is the Registered Nurse qualification. The latter is a promising step in career advancement.

The rewards for completing the nursing programme are appealing, but the penalties for noncompletion are severe. In general, students in the nursing programme are sponsored by their employers. Non-completion of NU101C usually means that the sponsorship is lost. Without the 
sponsorship, many students can hardly complete the programme. At present, completing the Higher Diploma in Nursing programme offered by the OUHK is the only means in Hong Kong for Enrolled Nurses to upgrade to Registered Nurses. Students who do not complete the programme will have no chance of promotion in the nursing profession and their salary will be barred at a lower level.

Comparatively, both the rewards for completing M122 and penalties for not completing it are rather mild. Students generally study this course for a degree programme. Scholarships and sponsorships are usually not available for studying either the course or the programme. In addition, the positive impact of completing the course and even the programme, on career for example, is not obvious in general. On the other hand, the implications of failing M122 are usually limited and not critical. Despite the failure will not be a pleasant experience and may discourage some students, its real impact on students may be just a delay of graduation. In the current system, however, the affected students generally have the flexibility to adjust their study schedules for minimizing the delay.

\section{IMPLICATIONS OF THE DIFFERENCES IN PRACTICE}

Based on the different characteristics identified between NU101C and M122 and the situation of NU101C observed in its course presentations, this section will discuss the implications of the differences in practice. The findings will be summarized into four categories, namely, student characteristics on entry, motivation and persistence on study, personal relationships, and hurdles for course completion.

\section{Student Characteristics on Entry}

Both NU101C and M122 adopt an open assess policy, but the nature and entry requirements of the nursing programme will discourage most, if not all, of the unqualified people from enrolling on its courses. For the unqualified applicants, NU101C will provide counselling and advice. As a result, all of the students of NU101C have very similar characteristics and are generally well prepared on entry. In brief, they start the nursing programme at the same time, take NU101C as the first course and follow closely the pre-determined study schedule. In addition, most of them are full-time practising Enrolled Nurses and supported by their employers. They have a clear goal for their studies and are prepared to commit into a threeyear programme. Finally, the entry requirements ensure that the nursing students have possessed the background knowledge and experience required for studying NU101C.

\section{Personal Relationships}

All students of NU101C are new to the system and may encounter similar study problems and frustrations. Since the students possess many similar characteristics, they can easily understand and accept each other and establish a close relationship. The face-to-face requirement forces the students to meet each other and therefore provides opportunities for them to interact and develop the relationship. This relationship enhances peer support as the students will share their learning resources, solve their study problems together, and share with and encourage each other. 
In addition to the peer relationship, the face-to-face requirement and arrangement of student representatives also help developing the student-tutor and student-coordinator relationships. These relationships allow the tutors and coordinator to be helpful resources to the students. The tutors and coordinator are nursing people and have professional connections. They can understand the current practice and future trend of the profession, integrate the contents of NU101C to students' daily workings, and visualize the impact of academic performance on students' career. As a result, they can communicate effectively with their students using the same professional language, and provide very concrete and reliable advice to the students.

\section{Motivation and Persistence on Study}

Most of the nursing students are motivated to study by a desire for career advancement. This desire may come with some pressure if some of their colleagues have been studying or even completed the programme. In general, their initial motivation must be very strong as they are committing into a three-year project. In addition, they need to start with two courses at the same time based on the pre-determined study schedule. This certainly requires a larger initial commitment than that of a typical new M122 student who starts with only one course for trial purposes. A larger commitment usually implies a stronger persistence on the course.

The personal desire drives the nursing students to have a clear goal at a higher level, that is, completing the programme instead of just NU101C. The pre-determined study schedule has shown them a path to this goal. Seeing the whole picture allows the students to prepare better before being enrolled on the course and plan ahead for their studies. This definitely enhances their persistence on the course. The personal relationships and support, and the penalties of non-completion also help enhancing their persistence but possibly from different directions. The rewards, though not guaranteed, can motivate the students to a certain extent.

Lastly, since there is a face-to-face requirement for the nursing students taking NU101C, the attendance records provide checkpoints for the tutors and course coordinator to identify and follow up the at-risk students.

\section{Hurdles for Course Completion}

With reference to the pre-determined study schedule, the nursing students generally start with two foundation courses including NU101C. This arrangement requires them to have a larger initial commitment and at the same time prevents the over-ambitious students from taking too many courses and being overloaded. Since the two foundation courses are arranged together, crushes in their tutorial schedules and assessment dates are avoided. In addition, since the two courses have the same design and structure and are delivered in similar styles, confusions and adjustments for taking two courses are reduced.

Students enrolling on an open and distance learning course are often discouraged by having unfit backgrounds and learning needs. In addition, new students may easily feel that they are isolated and their difficulties are unique. NU101C is designed for a specific group of students having similar backgrounds and these problems do not exist. For instance, its contents and study materials are specially designed to fit the new nursing students. Moreover, the similar student backgrounds facilitate the tutors and course coordinator to identify general problems in 
the class and provide focused support. Finally, using Chinese as the medium of instruction eliminates the language barrier for many Hong Kong students.

\section{RECOMMENDATIONS FOR IMPROVING COMPLETION RATE}

Based on the differences between NU101C and M122 and their implications in practice, this section will address the student attrition problem by defining four approaches for improving the completion rate of an open and distance learning course and recommending practices for applying these approaches.

\section{Enhancing Students' Quality}

As students are the ones who perform the study, their quality on entry will certainly affect their study outcomes. Research results have shown that the background characteristics of students are significant factors affecting their completion on a course (Kember, 1989; Sweet, 1986). In general, little work can be done to enhance students' quality before enrollment and it may be too late after that. The $\mathrm{NU} 101 \mathrm{C}$ results show that imposing entry requirements is a simple and effective means to raise the overall students' quality since all the unqualified applicants have been rejected; however, this means against the philosophy of open assess adopted by the university. For enhancing the students' quality, some practices in NU101C may be useful.

Pre-enrolled seminars are a common activity to introduce potential students to the university. After attending the seminars, the potential students are expected to understand better whether they should apply for particular courses. Nevertheless, experience has shown that potential students tend to ignore the pre-enrolled seminars. Many of them simply are not aware of the seminars. To give the potential students a final reminder (or warning), a simple list of preenrolled activities and contact people can be included in the registration form. In addition, a statement encouraging potential students, new students in particular, to attend the activities and seek for personal advice before enrollment can be placed on the top of the form.

In addition to pre-enrolled seminars, pre-enrolled counselling is usually provided for assisting individual potential students to clarify their study goals and define reasonable expectations on their own conditions. Experience has also shown that pre-enrolled counselling may not be an attractive service to potential students. The practice in NU101C, however, suggests that some information presented in the counselling can be very useful to potential students. Based on this finding, it is recommended to prepare a study schedule for each programme including its expected workload and challenges of the related courses. These schedules aim to give the potential students a better understanding of the required commitments and encourage them to consider their studies at both the course and programme levels before enrollment.

Finally, for the less qualified students who have enrolled on a course, post-enrolled support can be provided as soon as possible after the course presentation starts. Extra classes or study notes can be arranged for the weaker students to pick up if resources are available. If the number of weaker students is consistently large, the course coordinator may need to consider revising the course materials to include the preliminaries for a formal review. 


\section{Strengthening Personal Support}

Student support is a major issue in open and distance education and personal support can be of great value (Croft, 1991). Although distance learners usually need to study independently, the experience from NU101C has shown that relationships among students, tutors and course coordinator can be developed to enhance students' performance. These relationships are effective channels for students to obtain personal support. They also help the tutors and coordinator to understand better the course presentation and their students, and respond to any problems efficiently.

Participation in face-to-face activities is an effective means to develop personal relationships. In distance education, however, face-to-face activities are limited and their attendance is usually not required. For better personal support, students should be encouraged to attend face-to-face activities, at least in the initial period. Informal group works such as discussions, debates and presentations can be arranged within individual tutorial groups to promote student participation and interaction. This is a valuable opportunity for students to form peer-support groups and develop supportive relationships.

Tutors play the roles as facilitators in students' learning. For promoting personal support, it would be desirable to recruit tutors with relevant experience, teaching or learning experience in open and distance education for example, in addition to academic qualifications. Appropriate and timely support is effective in establishing student-tutor relationships as well as preventing student attrition (Case and Elliott, 1997). Tutors are therefore advised to take the initiative to contact their students, especially those who do not attend tutorials and have not submitted the first assignment, at an early stage of the course presentation.

In distance education, distant relationships are generally adopted between students and course coordinators. As it is common to have different coordinators for different courses, developing solid student-coordinator relationships is further hindered. As a key person of a course, the course coordinator is expected to have a first-hand understanding and concern for student affairs. For providing effective personal support, it is suggested that the coordinator should present a clear coordination image to the students and take a more active role in establishing the student-coordinator relationship. Regular tutorial visits, participation in online discussion and prompt replies to students' queries are just examples for serving this purpose.

Finally, for the various relationships to work efficiently and effectively as channels for personal support, students need to be advised, encouraged and reminded to take the initiative to share their study problems and provide support to each other, and contact tutors and course coordinators for further assistance.

\section{Maintaining Students' Motivation and Enhancing Their Persistence}

Adult learners generally involve in family, career and many other commitments. When they find that the situations are not manageable, some of them will choose to defer or even give up their studies. For foundation courses, the initial dropout rates are particularly high (Fan and Chan, 1999). This result is not surprising as taking a foundation course is usually just the first step of a long study journey and the penalty of dropping out is relatively small. Motivation and 
persistence have been identified as significant factors affecting student completion. It is reasonable to assume that the students generally have some motivation and persistence when they apply for and enroll on a course. Many of them simply cannot keep up with their initial motivation and persistence. For maintaining the motivation and enhancing the persistence of individual students, some practices are suggested from the experience of NU101C.

In general, uncertainty discourages people and better understanding enhances persistence. The experience from NU101C suggests that a sample study schedule can be helpful for enhancing students' persistence. The schedule presents to students a study path with an ending. The path does not only define a goal, it also facilitates students to plan ahead for better time management between studies and other commitments. The schedule is particularly helpful for students who are new to the system. For these new students, a full picture and some study guidelines are more meaningful than simply flexible learning and self-pacing.

To keep students being motivated throughout their studies, short-term and achievable targets can be defined for them. In addition, scholarships, awards or even letters of appreciation can be provided for outstanding academic performance. In a recent study, Fan (2004) introduced follow-up questions on written assignments to encourage students to improve their workings and found that the completion rate increased significantly. This result has shown that even a small reward can lead to a large improvement.

Associating courses and programmes with professional bodies can raise their professional status and therefore encourage students to complete them. In general, this association may provide students with a better chance of success in their career, but career advancement can hardly be guaranteed. Students should not be misled to have unrealistic expectations on their studies. After all, the courses and programmes themselves are designed to develop the study interest of their students.

Finally, exemption of study credits for relevant working experience (in addition to academic qualifications) can be introduced as a standard practice at the programme level. This practice does not only promote lifelong learning, but also encourages students to stay for completion. The exemption implies saving time and money on study; nevertheless, it will be meaningful only if the students complete the intended programmes.

\section{Removing Unnecessary Hurdles}

Hurdles can be positive challenges encouraging students for better performances; they can also be negative factors inviting non-completions. From a practical point of view, hurdles may not be completely avoided and sometimes are necessary. For efficient teaching and learning, however, unnecessary hurdles should be removed. This is particularly important for part-time adult learners. These adults generally have many commitments and may need to cope with various age-related problems. They have very limited time for their studies and cannot afford to waste it.

Experiences from NU101C and the nursing programme have suggested some practices for removing the unnecessary hurdles. In general, a consistent course structure and presentation 
style can be adopted for different courses in the same programme so that students will not need to spend extra effort in adaptation and adverse consequences due to confusions can be avoided. In addition, the tutorial and assessment schedules of related courses can be arranged as a whole to eliminate as much time conflicts as possible. For the new students, assistance can be provided for them to adapt to the system and develop various personal relationships. Finally, for courses that are not delivered in the students' mother language, initial language support can be arranged.

\section{CONCLUSION}

In view of the high student attrition rate in open and distance education and a knowledge gap regarding the attrition, this study adopts an integrated approach to examine the attrition issue at the course level. Through a systematic and thorough analysis on the differences between a high-achieving course and a low-achieving course, implications are drawn regarding factors and practices that facilitate student learning and subsequently lead to better completion rates. Based on these implications, a number of recommendations are made. Some of them can be applied directly while the others may need to be adjusted in practice. In summary, these recommendations stress on improving students' quality, strengthening personal support, maintaining students' motivation and enhancing their persistence, and finally, removing unnecessary hurdles. To conclude, the findings in this study facilitate educators in open and distance education to manage the attrition problem at the course and even programme level and search for alternative solutions to this long-standing problem. For further research, the effectiveness and practical problems of applying the recommendations will be studied.

\section{REFERENCES}

Case, P.S. \& Elliott, B. (1997). Attrition and retention in distance learning programs: problems, strategies solutions. Open Praxis, 1, 30-33.

Croft, M. (1991). Student support services: an overview. Report on Round Table on Student Support Services, 3-30, Commonwealth of Learning, Canada.

Fan, R. \& Chan, M. (1999). A study of student attrition in foundation courses. Open Education Research, 4, 21-6.

Fan, R. (2004). Using follow-up questions in tutor-marked assignments: issues and implications. Proceedings of the 18th Annual Conference of the Asian Association of Open Universities, Shanghai, CD-ROM.

Kember, D. (1989). An illustration, with case studies, of a linear-process model of drop-out from distance education. Distance Education, 10(2), 196-211.

Sweet, R. (1986). Student dropout in distance education: an application of Tinto's model. Distance Education, 7(2): 201:13.

Taplin, M., Yum, J., Jegede, O., Fan, R., \& Chan, M. (2001) Help-seeking strategies used by high-achieving and low-achieving distance education students. Journal of Distance Education, 16, 56-69. 